\title{
When will MEMS switches be ready for commercial products?
}

\section{Introduction}

Microelectromechanical systems (MEMS) and advanced microsystem devices have matured significantly over the last 20 years and are currently used in automobiles, cellular phones, printers, and overhead projectors. ${ }^{1}$ MEMS switches are viewed by many as paramount for next generation radio frequency (RF) circuits and applications due to their extremely low power consumption (i.e. $0 \mathrm{~W}$ for electrostatically actuated devices), small geometries over conventional technologies, and superior RF performance (i.e. low insertion loss: $\sim 0.2 \mathrm{~dB}$ and high isolation: $20-30 \mathrm{~dB}) .^{2}$ In addition, metal contact micro-switches have great potential for a wide variety of applications due to their broadband operation (i.e. DC-40GHz). The RF MEMS switch, however, has not yet made it to "prime time" due to its perceived limitations in both performance (i.e. stable electrical contact resistance) and reliability (i.e. lifetime). Let me explain the perceived limitations and how I see a way forward to commercialization. First, the original specifications for RF MEMS switches were $<1 \mathrm{~dB}$ insertion loss and $>1 \times 10^{12}$ switching cycles. I believe these specifications were originally based on using RF MEMS switches to replace transistor switches onboard satellites. Unfortunately, this original specification has become the "gold standard" for all applications. Next, the majority of RF MEMS switch researchers have primarily focused on either searching for the "holy grail" electrical contact material or on designing innovative, high contact force, mechanical switch designs (i.e. actuators). Both of these approaches are attempts to "engineer away" poor performance and reliability with either a special contact material or a better actuator. Unfortunately, most of these efforts have done little to actually improve micro-switch performance and/or reliability. As of today, I am aware of only one viable company that is pursuing the manufacture of microswitches and several companies that have gone out of business. ${ }^{3}$ There are, however, a few companies that have in-house research projects to develop micro-switches for their own products. ${ }^{3}$ I believe the way forward to commercialization MEMS switches is to first study the fundamentals of micro-contact physics and thin film metallurgy in a meaningful way. What does this mean? First, as a community MEMS switch researchers need to focus on the root causes of device failure not just avoiding failures. For example, when studying the electrical contact it should be decoupled from the mechanical switch design so that the micro-contact physics can be studied directly. The results of these fundamental studies could then be used to design micro-contacts suitable for micro-switches.

This is how macro-switch designers study switching phenomena. Next, as a community MEMS researchers need to engage with Industry to obtain realistic specifications for true applications. Are one Trillion switching cycles truly required for all applications? Cell phones? Automotive? Relays? Certainly not, but if you ask an integration engineer from the cell phone or automotive industry they will cite "poor reliability" (i.e. $<1$ Trillion cycles) as the primary reason for not using MEMS switches in these applications. ${ }^{3}$ Recent studies in micro-contacts include various dedicated test
Volume 3 Issue 4 - 2017

\author{
Ronald A Coutu Jr \\ Marquette University, USA
}

Correspondence: Ronald A Coutu, Marquette University, 1637 WWisconsin Ave, Milwaukee, WI, USA, Tel + I (4I4) 288-73।6, Email Ronald.Coutu@marquette.edu

Received: November 03, 2017 | Published: November 14, 2017

fixture approaches including: actual MEMS switches, atomic force microscopes (AFM), scanning tunneling microscopes (STM), and nanoindentors, have been used to collect the micro-contact data (i.e. contact resistance and contact force). Although these new approaches are encouraging, each of the above methods has severe limitations. For example, MEMS switches work well for lifecycle testing but not for measuring contact force which must be inferred through modeling. Additionally, AFM/STM and nanoindentor -based test fixtures allow direct contact force measurement but at extremely low cycle rates (i.e. $10-100 \mathrm{~Hz}$ ). Another restriction is the inability to test contacts in controlled ambient environments for contamination control. $^{4-9}$ In my group, we study micro-contacts using a dedicated novel test fixture, housed in a controlled $\mathrm{N}_{2}$ ambient environment, capable of both "hot" and "cold" switched initial contact and cycled contact testing up to $3 \mathrm{KHz}$. Contact force and resistance data are simultaneously collected, in-situ, while applying a calibrated external $\mu \mathrm{N}$ load to a MEMS micro-contact support structure (i.e. not a switch) configured as a Holm cross-bar test. ${ }^{10}$ Using this unique apparatus, we have explored and characterized the performance and reliability of novel material micro-contacts such as: $\mathrm{Au}-\mathrm{Au}, \mathrm{Au} / \mathrm{CNT}$ composite - $\mathrm{AU}, \mathrm{Au}-\mathrm{Ru}, \mathrm{Au}-\mathrm{RuO}_{\mathrm{x}}$, etc. In addition, we have studied engineered micro-contact geometries and pairs consisting of hemispherical upper contacts landing on either planar or 2D pyramid lower contacts. Additional studies in low-frequency AC, external circuit loadings, and DC polarity test have also been conducted. ${ }^{11-15}$ In summary, it's the opinion of this author that MEMS switches will continue to not be commercialized until the MEMS research community fully engages with Industry to obtain realistic specifications for real applications. Once realistic specifications are known, it is incumbent on MEMS researchers to conduct worthwhile, knowledge generating, studies to better understand the fundamentals of micro-contact physics.

\section{Acknowledgements}

The author thanks the Air Force Office of Scientific Research (AFOSR) for funding this research and Mr. Thomas Edleman, Mr. Benjamin Toler, Mr. Christopher Stilson, Dr. Told Laurvick, and Mr. Protap Mahanta for their participation in the supporting research.

\section{Conflict of interest}

The author declares no conflict of interest. 


\section{References}

1. Toler BF, Coutu RA, Mc Bride JW. A review of micro-contact physics for microelectromechanical systems (MEMS) metal contact switches. IOP Journal of Microengineering and Micromechanics. 2013;23(10):103001.

2. Yao ZJ, Chen S, Eshelmanm S, et al. Micromachined low-loss microwave switches. Journal of Microelectromechanical Systems. 1999;8(2):129134.

3. Personal communication during the I-Corps Milwaukee Program: 36 interviews with Industry; 2017.

4. Coutu RA, Reid, Cortez R, et al. Microswitches with sputtered Au, AuPd $\mathrm{Au}-\mathrm{on}-\mathrm{AuPt}$, and $\mathrm{AuPtCu}$ Alloy Electric Contacts. IEEE Transactions on Components \& Packaging Technologies. 2006;29(2):341-349.

5. Coutu RA, Kladitis PE, Leedy K, et al. Selecting metal allow electric contact materials for MEMS switches. Journal of Micromechanical Microengineering. 2004; $14: 1157$.

6. Yang Z, Lichtenwalner D, Morris A, et al. A new test facility for efficien evaluation of MEMS contact materials. Micromechanics and Microengineering. 2007;17(9):1788.

7. Chen 1, Lee H, Guo ZJ, et al. Contact resistance study of nobel metals and alloy films using a scanning probe microscope test station. Applied Physics. 2007; 102:074910.

8. Majumder S, Mc Gruer NE, Adams GG, et al. Contact resistance study of nobel metals and alloy films using a scanning probe microscope test station $\mathrm{j}$ study of contacts in an electrostatically actuated microswitch. Sensors and Acuators A: Physical. 2001;93(1):19-26.
9. Kogut L, Komvopolous K. Electrical contact resistance theory for conductive rough surfaces. American Institute of Physics. 2003;94(5):31353162 .

10. Holm R. Electric Contacts: theory and application. Berlin \& Heidelberg, Germany: Springer-Verlag; 1967. 484 p.

11. Edelmann TA, Coutu RA. Microswitch lifecycle test fixture for simultaneously measuring contact resistance $(\mathrm{Rc})$ and contact force $(\mathrm{Fc})$ in controlled ambient environments. Proceedings of the $56^{\text {th }}$ IEEE Holm conference on electrical contacts; USA: IEEE; 2010. p. 309-316.

12. Stilson CL, Coutu RA. Micro-contact resistance of Au/Au on Engineered contact surfaces using grayscale lithography. The $27^{\text {th }}$ international conference on electrical contacts; Germany: IEEE; 2014. p. 1-6.

13. Stilson CL, Toler BF, Coutu RA. Micro-contact performance characterization of carbon nanotube (CNT)-Au composite micro-COntacts. Proceedings of the $59^{\text {th }}$ IEEE Holm conference on electrical contacts; USA: IEEE; 2013. p. 358-365.

14. Stilson CL, Coutu RA. Reliability evolution of $\mathrm{Au} / \mathrm{Au}, \mathrm{Au} / \mathrm{Ru}$ and $\mathrm{Au} /$ $\mathrm{RuO} 2$ micro-contacts. The $27^{\text {th }}$ international conference on electrical contacts; Germany: IEEE; 2004 p. 1-6.

15. Laurvick TV, Coutu, RA. Improving gold/gold micro-contact performance and reliability under low frequency AC through circuit loading. IEEE Transactions on Components, Packaging and Manufacturing Technology. 2017;7(3):345-353 